Research Article

\title{
Climate Responsive Design Simulation and Modelling for Industrial Heritage
}

\author{
Manuel V. Castilla \\ University of Seville, Sevilla, Spain \\ Correspondence should be addressed to Manuel V. Castilla; mviggo@us.es
}

Received 31 December 2017; Revised 17 March 2018; Accepted 2 April 2018; Published 9 May 2018

Academic Editor: Ricardo Perera

Copyright (C) 2018 Manuel V. Castilla. This is an open access article distributed under the Creative Commons Attribution License, which permits unrestricted use, distribution, and reproduction in any medium, provided the original work is properly cited.

\begin{abstract}
The control of solar radiation is a basic dimension of modern design in all different types of constructions. Many architects have recently observed that different phases of sustainable design require a set of calculations and simulations that are necessary as a new standard design. The valuable contributions to the process of sustainable design has a common denominator: solar radiation and comfort. In this way, motivated by all these new strategies and concepts, the large number of papers published suggests that the work has not been finished. This work provides an illustration of the Atarazanas regarding its climate responsiveness, focusing specifically on daylighting, shading, heat gain, and cooling loads. The objective is to assess the design of the Reales Atarazanas de Sevilla (Seville Royal Dockyards) to quantify how it is impacted by solar insolation and to provide insights about design characteristics that influence efficiency and conservation.
\end{abstract}

\section{Introduction}

In recent years, research has focused mainly on the development of scientific and technological tools to improve the energy performance of buildings as well as their lighting conditions. Climatological factors, solar radiation, daylight, and environmental conditions are providing important data for architectural design. In this sense, there is an abundant scientific literature on the process of sustainable building design.

The concept of sustainability has different meanings when it comes to sustainable design [1]. Since the 1990s, the building sector has recognized that its activity has a major impact on the environment and has changed the way buildings are designed to mitigate environmental impacts. One of the objectives of architectural design is the creation of a satisfactory and healthy environment in which we can carry out our activities, whether residential, recreational, educational, or working. Consequently, given the growing complexity of architectural design, research at integrated environments where data and tools are handled plays an important role in the sustainable design process $[2,3]$. This is precisely because of its great influence on comfort, economy, quality of life, and health. It should be noted in general that the valuable contributions to the process of sustainable design has a common denominator: solar radiation and comfort [4-7]. In this way, motivated by all these new strategies and concepts, the large number of papers published suggests that the work has not been finished.

This work is a review of a masterpiece of industrial heritage architecture: the Reales Atarazanas de Sevilla (Seville Royal Dockyards), (Figure 1).

A critical examination of the Atarazanas allows an insight into specific design characteristics that impact energy efficiency and conservation. The building is located in the Arenal district next to the Guadalquivir River in the heart of the city. Its origins are intimately linked to the King Alfonso $\mathrm{X}$ of Castile (1221-1284) and to the privileges that his father gave to sailors, fishermen, and so on, as discussed by Bello and Martín [8] established in the neighbourhood Barrio de la Mar which was created after the conquest of Seville. Its location was ideal to fulfil the function of shipyard due to the Guadalquivir course, at that time, used to be wider. Although this situation was chosen specifically for being near to the river, the evolution of the city of Seville has made it an excellent location for any new use of the building and its architecture. 


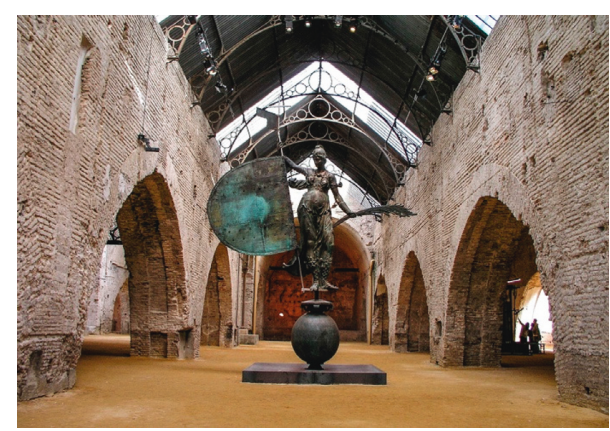

Figure 1: Reales Atarazanas de Sevilla (Seville Royal Dockyards).

Architecturally, it is an immense Gothic and Mudejarstyle work built in brick masonry, a symbiosis of techniques and ways of creating architecture resulting from Muslim and Christian cultures living side by side. The enormous dimensions of the wide and long naves covered by arched vaults are astoundingly suitable for the construction of the largest ships of the time, Figure 2, naves 1-7 (left to right). These naves are connected to each other laterally through thick, slightly pointed arches facing each other that begin directly from the ground and which in their entirety provoke interior perspectives of an unusual beauty (Figure 3).

This work provides an analysis of the Atarazanas regarding to its climate responsiveness, focusing specifically on daylighting, shading, heat gain, and cooling loads. The objective is to assess the design of the Atarazanas to quantify how it is impacted by solar insolation and to provide insights about design characteristics that influence efficiency and conservation. Specially, it is examined the design strategies such as the orientation and sun-screening and their effect on daylighting, shading, and heat gain. The analysis is based on a conceptual framework design model giving support to architects and engineers to increase the efficiency of the passive architectural-collaborative process in industrial heritage. The essential features of the suggested methodological model can be summarized as follows:

(i) This work applies concepts of environmental design and proposes a more comprehensive integrated environment for architectural heritage.

(ii) The suggested method is developed as an integrated framework, which includes multiple design tools and data to be analysed.

\section{Methodology}

Industrial heritage represents a considerable qualitative and quantitative economic potential for future development. In this context, architects and engineers often find themselves in the role of mediators between investors, scientific, community, monument preservation, and general public. An active cooperation and interaction between them is lacking. That causes confusion, misunderstanding, and negative attitude towards each other. The result of architectural activity (inactivity) is crucial not only in terms of design, but also has a significant impact on the opportunities of education and raising awareness. This happens during the

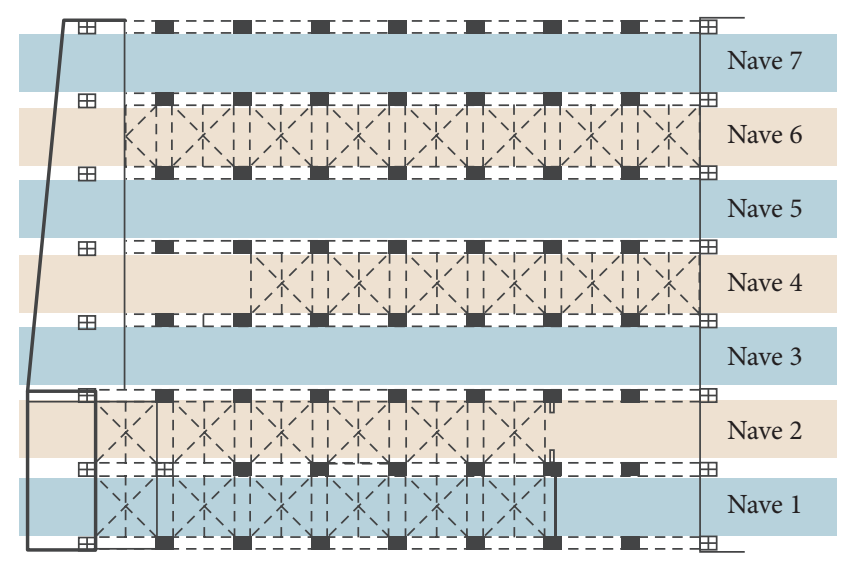

Figure 2: Floor plan, naves 1-7, Reales Atarazanas de Sevilla (Seville Royal Dockyards).

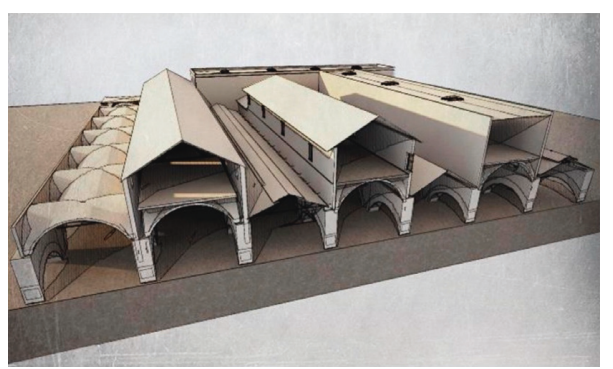

FIGURE 3: 3D rendering image, sectional drawing, naves 1-7 (left to right), Reales Atarazanas de Sevilla (Seville Royal Dockyards).

whole process of care and conservation of industrial heritage. In the given circumstances, the transfer of the research results from futuristic disciplines requires more detailed attention.

The essential features of the suggested methodological model can be summarized as follows:

(i) This work applies concepts of environmental design and proposes a more comprehensive integrated environment for architectural heritage.

(ii) The suggested method is developed as an integrated framework, which includes multiple design tools and data to be analysed.

Design may be defined as the process in which an idea is developed, simulated, and elaborated into detailed instructions and working tools for the final materialisation. The process design will focus on three main phases where different tools from different fields may handle each phase. Therefore, it is necessary to prepare these tools into an integrated way for every phase. The research can be divided into three main phases: conceptual phase, simulated analysis, and materialization phase.

Each phase has assigned its proper tools and collection dates, which converge into an integrated environment. This integration is not a single-tool property; on the contrary, it is the final result among relationships with other elements in the environment, covering in this way the whole process. Tool integration is about the extent to which these tools 


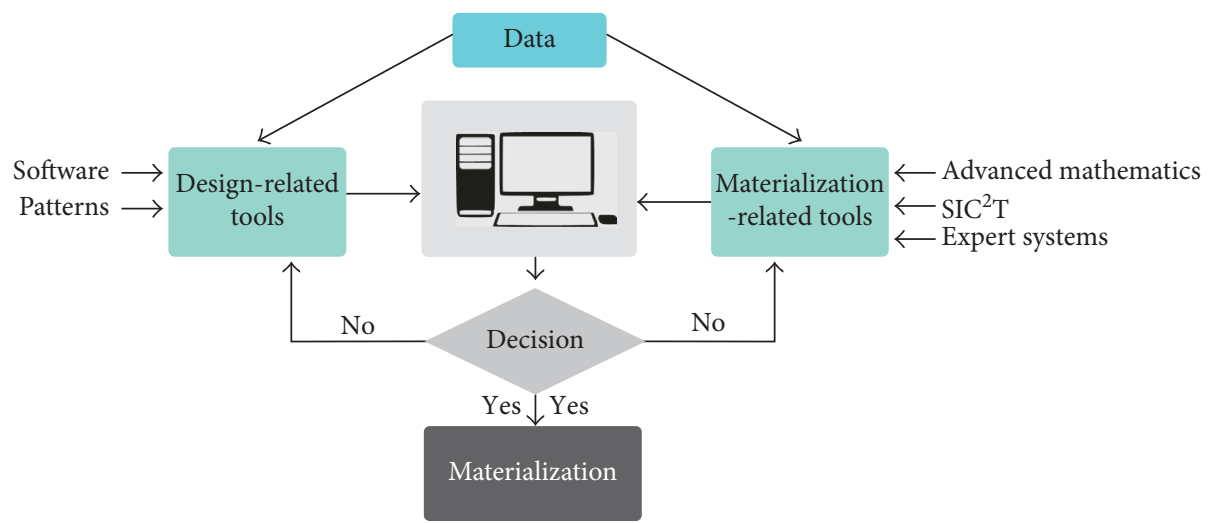

Figure 4: The scheme illustrates the workflow method. This model is built upon 4 hierarchical steps: (1) Data collection; (2) simulation analysis; (3) decision; (4) materialization.

agree [9]. In this way, any integrated environment can be viewed as a composition of the three basic multitool groups:

(i) Group 1: creative design related tools: conceptual phase.

(ii) Group 2: data related tools: simulation analysis.

(iii) Group 3: materialization process related tools: evaluation, optimization, and materialization.

Each group of tools provides those requirements that the system needs to achieve the target. Once it is processed, these become a part of the knowledge base to achieve the result and the intervention.

2.1. Multitool Integrated Design Environment. The system, which has to be developed, integrates various areas of design and generates a continuous feedback during all design process.

The proposed conceptual model is a novel system that emphasizes identification and differentiation of some partially resolved design elements through the storage and manipulation of different levels of design resolution information. The model aims to assist the building design process to become an integral part of an overall collaborative working environment. The different tools should be integrated in a modular and efficient environment. The intersection of all these three multitool groups defines the integrated environment (Figure 4).

2.1.1. Step 1: Data Collection. All of the model's inputs are organized. These inputs may be grouped under two categories: constant values and variables values. A main area in which computer science may support the designer is exchanging and processing data. These data will have to be ordered and processed very efficiently but the problem is how to order this data so that it can be easily processed. This requires a reliable data model. To solve this problem, it is absolutely necessary to organize the information as a layered structure that includes different levels of data, which are arranged hierarchically. In this respect, the hierarchically layered tool structure is well aligned with the structure of the task environment, which is hierarchical in its composition.

2.1.2. Step 2: Simulation Analysis. In this methodology, the physical environment factors are classified into three components: daylight efficiency, thermal comfort, and energy efficiency (Section 3). Each component consists of various factors, which are analysed to come up with useful data. The modules used in this proposed model are specific to the scope of the study. The analysis results can easily be obtained by using new generation design programs integrated.

2.1.3. Step 3: Decision. Parallel to the advancements in computer technology, there is a need for enhanced information processing virtually in all disciplines to handle all the incoming information; this is basically due to growing data and information processing as demand of modern technologies. In this way, we focus on the development of a new design tool using mathematical methods and other techniques and disciplines. The purpose is that the advanced simulation will be used throughout the design process, but with interfaces, software functionality, defaults, and results analysis tailored to the requirements of all design stages. In process technology, one of the primary rules is that each step must be clearly related to the final goal and must be tested and evaluated to this purpose.

2.1.4. Step 4: Materialization. In the materialization phase, the question arises how to determine which material, element, or aspect will best satisfy all requirements regarding costs, installations, and aesthetic details. In this process, there is a great need for applied knowledge, physics and mathematics, material science, and so on. Before the developments of the $\mathrm{SIC}^{2} \mathrm{~T}$ (science, information, communication, and computer technology), almost every decision was based on our knowledge and experience. Nowadays, with the development of new technologies, much software has been written for specific problems, but still there is no software available which can integrate these different concepts in 

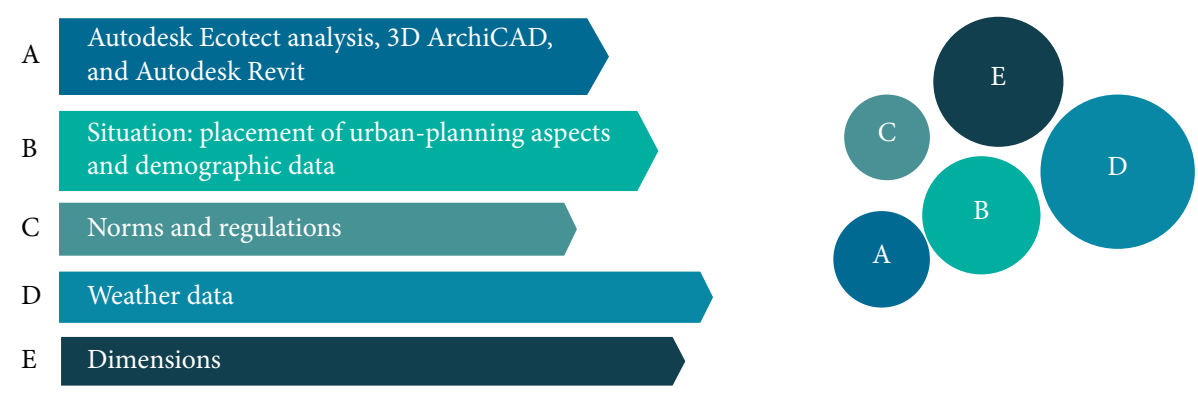

FIgURE 5: Conceptual and simulation phases design related tools.

science, information, communication, and computing technology into one system to support the designer while taking decisions. Generally, the expert knowledge can be stored and made accessible by means of an expert system. Thus, the creative process is a practice which is the mixture of deductive and inductive processes.

The advantages of the proposed model include

(i) The suggested multitool approach can provide modularity, flexibility, and extensibility in terms of behaviour control and system performance tools.

(ii) Conceptual design, simulation, and materialization are three inseparable stages: conceptual, simulation, and materialization.

(iii) The support of several users running parallel multiple design tasks on different design projects.

(iv) Dividing functionality amongst multiple tools will increase system efficiency.

(v) Multiple tools can improve the dynamics of the integrated software environment.

The proposed methodology to achieve these objectives comprises the above theoretical work, making use of computer simulation apps and a case study to illustrate the clear advantages of the suggested integrated decision model.

\section{Implementation and Simulation of Lightning Analysis in Industrial Heritage}

The objective of this work is to provide an illustration of the Atarazanas regarding its climate responsiveness, focusing specifically on daylighting, shading, and solar radiation as discussed in [10]. Undoubtedly, any intervention on our industrial heritage links the past to the future throughout present projects and requires a strategy of design and adaptability that would not be necessary in new designs. This approach, the case study Reales Atarazanas is an important legacy. Consequently, ensuring the building in use is the best way to preserve it. Therefore, adapted reuse consists of a conversion of this monumental work keeping its heritage value and, if possible, its interpretation and understanding although accommodating other uses and new functions. The restoration and adaptation of industrial heritage from any technological dimension aims to add a new layer without eliminating the previous ones. However, this renovation is not the only important point, because adaptive complexity implies other essential aspects such as energy efficiency and lighting.

3.1. Climate. Understanding the climatic conditions of the Atarazanas contextualizes the analysis of this research. The city of Seville is considered a locality with characteristics of warm-temperate climate thanks to its geographical location, latitude, and its surroundings, with an average annual temperature of $19.2^{\circ} \mathrm{C}$ and moderate thermometric temperature oscillations in cold and warm periods. Winters are mild, with an average minimum temperature not lower than $5^{\circ} \mathrm{C}$, and summers are very hot and torrid, longer and hotter every year (the maximum extreme temperatures can be given from the month of May to the month of September). With this respect, scientists have studied a number of different indicators of solar activity over the years [11]. According to a study from AEMET (Agencia Estatal de Meteorología) (State Meteorological Agency), which covers all of the heatwaves in Spain between 1976 and June 2017 , temperatures above $46^{\circ} \mathrm{C}$ have rarely been seen in the country. Nevertheless, temperatures exceeding $45^{\circ} \mathrm{C}$ have been registered on five occasions since 2015, being increasingly the highest and most frequent temperatures ever registered.

3.2. Solar Data. Daylight is a key factor that directly affects thermal and comfort throughout its life; hence, it is an essential initial step in architecture $[12,13]$. The Atarazanas has west-southwest orientation as its main facade guarantees sun radiation throughout day hours in cold months and during the evenings the rest of the year. Nevertheless, the main reason for its orientation was the perpendicularity to the river, since its use was as a shipyard, and this particular orientation favoured a connection with the water.

To apply the suggested method, Figure 5 summarizes the parameters most relevant (tools and data) involved in the three multitool above mentioned. Chosen tools in Figure 5 allow us to estimate solar energy data, insolation, and illuminance for a specific period of time precisely, providing insights about design characteristics that will influence efficiently and may help to its correct preservation.

\section{Results and Discussion}

Analysis and simulation are important tools in daylighting design $[14,15]$. In general, analysis provides quantitative 


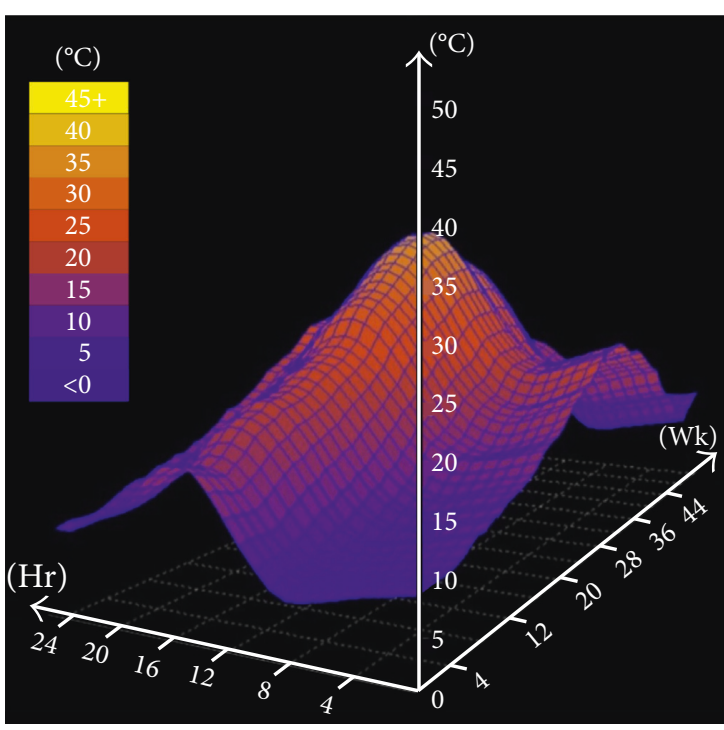

(a)

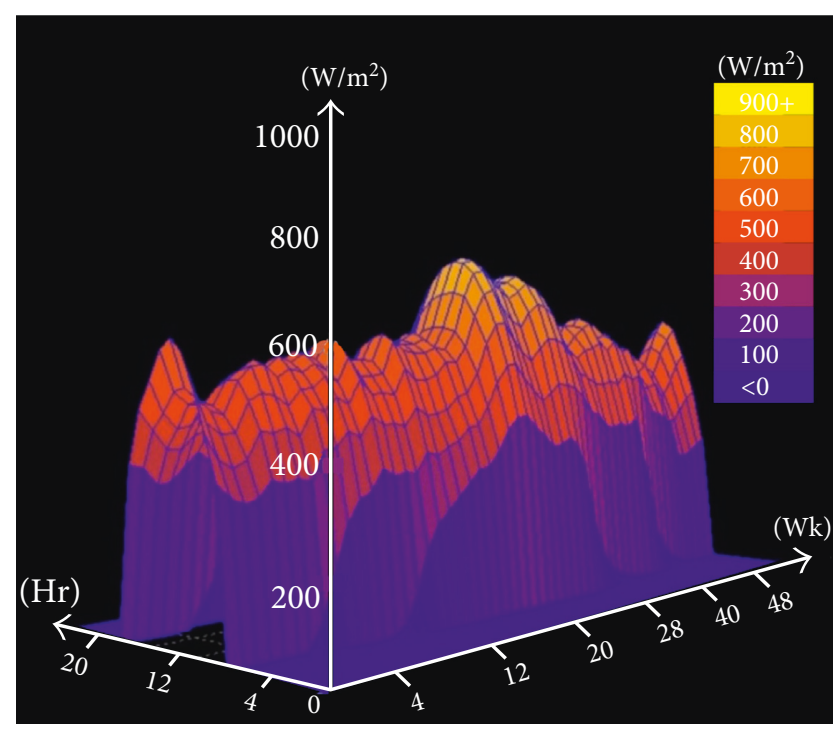

(b)

FIGURE 6: Graphs of average temperature and solar radiation, location Seville, Spain. (a) Weekly summary average temperature $\left({ }^{\circ} \mathrm{C}\right)$. (b) Weekly summary direct solar radiation $\left(\mathrm{W} / \mathrm{m}^{2}\right)$.

information (annual available natural light, solar shading analysis, etc.). In this case study, simulation is used to create a qualitative visual interpretation of what the space may actually be like in this model, Las Atarazanas, and it is illustrated through renderings of the different significant values and representations of natural light and solar radiation in the interior of the seven naves of the studied building. We cannot ignore that in many cases, as Las Atarazanas, the architectural heritage remains over the centuries. Thus, the application of this analysis tool allows for performance simulations that can significantly improve the design and improve interventions for a restoration of industrial heritage over its lifecycle.

4.1. Temperature. The temperature in Seville is a main climatic factor in which attention should be focused.

The temperature differential between hot and cold months can be defined as extreme. In summer, as is shown in Figure 6(a), peaks of more than $40^{\circ} \mathrm{C}$ are reached when the sun is incident perpendicularly. In winter time, temperature drops below $5^{\circ} \mathrm{C}$ in the early hours of the day. This great leap means that buildings must be prepared to withstand these variations both physically and structurally as well as in levels of thermal comfort.

The basic climate data introduced for the Weather Tool has been obtained from the Energy Plus website created by the United States Department of Energy and imported into the software Autodesk Ecotect Analysis. Latitude and longitude coordinates of Seville are 37.4, -5.9, and the elevation above sea level is $7 \mathrm{~m}$.

The incident light is $100 \%$ related to the temperatures reached in the interior of buildings. If this is not considered while designing, habitability can be compromised, and energy consumption could increase very high, as the walls absorb heat and transmit it to the interior.
It cannot be ignored that in Seville, and generally most of Andalusian cities, the architecture is well oriented to the protection of summer temperatures. As we can observe with this study, the orientation east-west (longitudinal axis of the seven naves in Las Atarazanas) allows a more uniform lighting and solar radiation, protecting the building from the southern component during hot summers in extremes conditions of temperatures such as those recorded in the city of Seville as showed before.

4.2. Solar Radiation. The distribution of radiation increases during the noon and reaches its peak during the summer months. As can be seen, there are no differences of such exaggeration as it is in the case of temperature, see Figure 6(b).

For very few periods of time, the temperature is between the thermal comfort levels.

It is noticed that diffuse solar radiation hardly varies during the year, always maintaining between 0.2 and $0.15 \mathrm{~kW} / \mathrm{m}^{2}$ (Figure 7).

4.3. Relative Humidity. The relative humidity throughout the year, peaks of $80-90 \%$ are observed during winter months and minimums of $20 \%$ in dry summer period.

The relative humidity increases during nights, and it reduces during the hours in which there is sunlight and temperature increases. Generally, Seville is a dry city, typical of the Mediterranean climate. This is due in part to its proximity to the Strait of Gibraltar, which channels the great currents of air from the Mediterranean and keeps away the storms coming from the Atlantic Ocean.

4.4. Solar Simulation: Summer and Winter Solstices. The simulation is based on two critical dates of the annual 


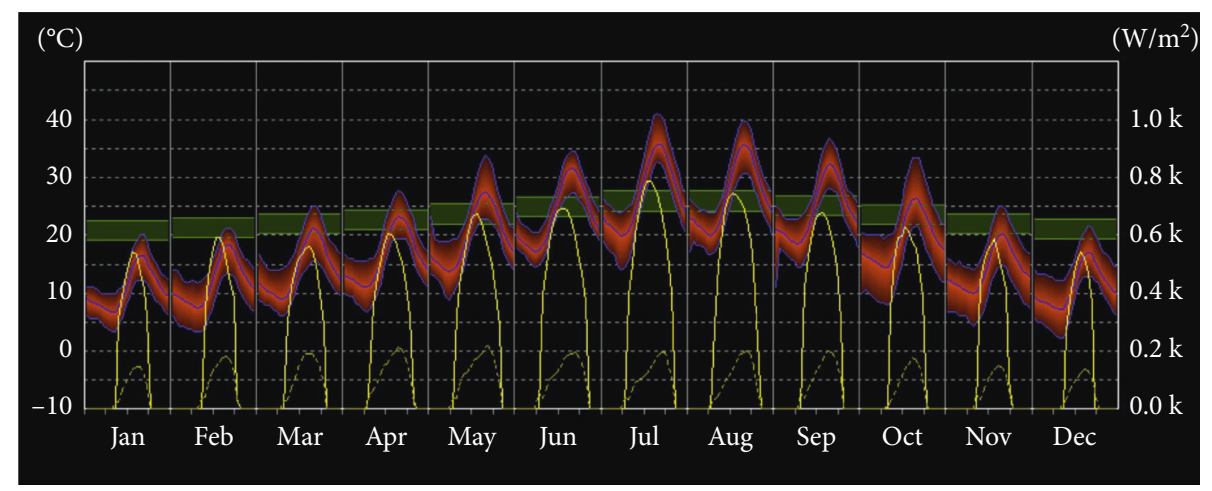

FIGURE 7: Graphs of monthly diurnal average temperatures, location Seville, Spain.

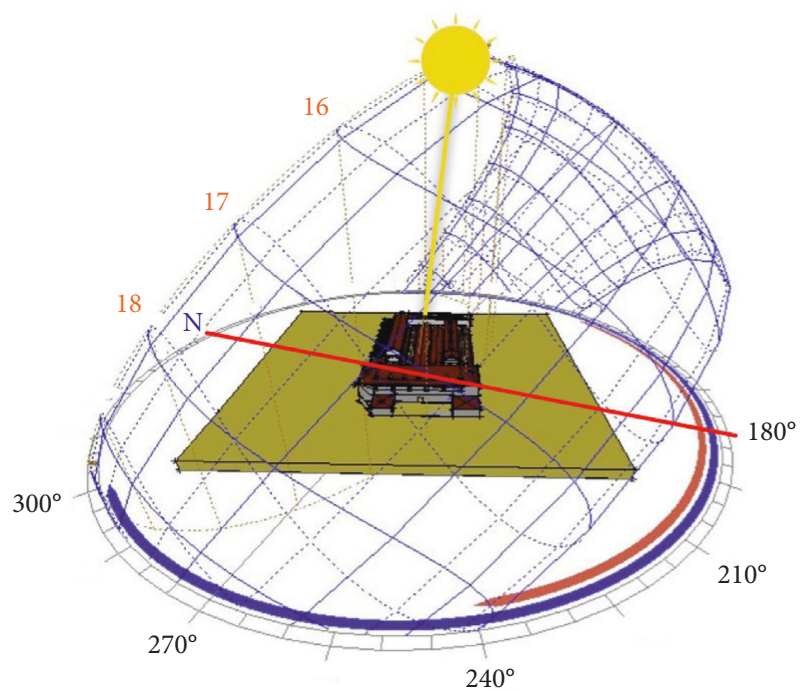

(a)

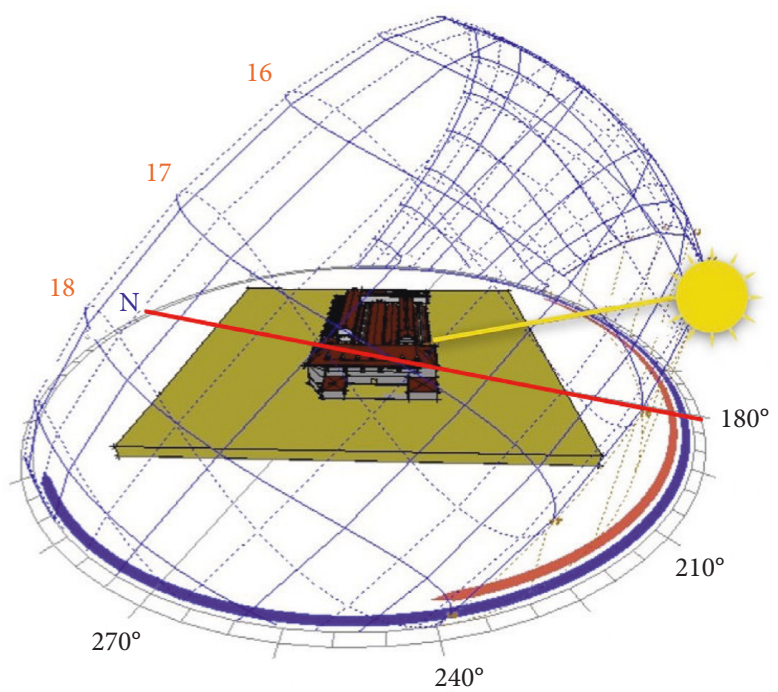

(b)

Figure 8: Solar simulation graphs. (a) Summer solstice, Atarazanas, Seville, Spain. (b) Winter solstice, Atarazanas, Seville, Spain.

calendar, June 21 and December 21, summer and winter solstices, respectively. These are the days when the periods of solar radiation are longer and shorter, and therefore, the days of more and less sunlight, see Figures 8 (a) and $8(\mathrm{~b})$. Thus, with the representation of the illuminance expressed in lux (lx), we can achieve a realistic simulation of the levels of natural light in the Atarazanas, the case study in this paper.

Lateral naves ( 1 and 7$)$ and all those that have roofs with translucent materials show illuminance levels of 250 lux approximately in less exposed areas. This level might be considered sufficient for basic tasks or a new use for exhibitions. However, the naves 2, 4, 5, and 6 do not reach such high levels (between 80 and 120 lux). This way, these naves would have to make some big interventions to get more lighting or directly make use of artificial lighting (Figures 9 and 10).

If this building is finally converted into a museum as a new use proposed by the city council of Seville, naves 1, 3, and 7 would have an almost perfect illuminance for this kind of activity.
Nave 3, in Figure 10, shows the levels of illuminance (lx). It is observed that values shown are considerably lower than those obtained for nave 1 on June 21 . The sun is located a lower angle, which translates into fewer incident rays and therefore less light. Thus, nave 3 has values below $25 \mathrm{~lx}$ in winter time, and therefore it would need artificial light support for the new use.

Focusing in the Atarazanas, with the realization of all the graphs and their subsequent analysis, we proceed to understand that some deficiencies appear and how they could be solved. First, we must mention that there is shortage of natural light in naves $2,4,5$, and 6 . This brings into the use of artificial lighting almost obligatorily to be able to perform any type of visual activity in the future.

It has also been seen that due to the current design of roofs, which supposedly light should enter to illuminate the building (naves 3 and 7), the light is hardly conducted through the building. 


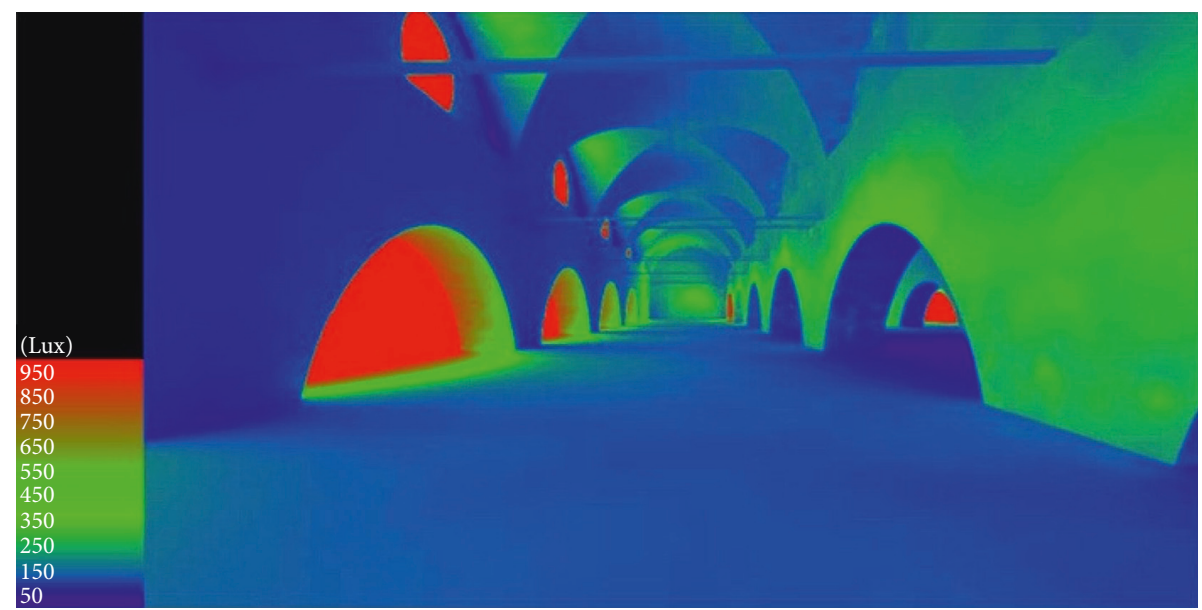

FIgURE 9: Natural daylight simulation, summer solstice. 3D illuminance representation (lx). Nave 1, Atarazanas, Seville, Spain.

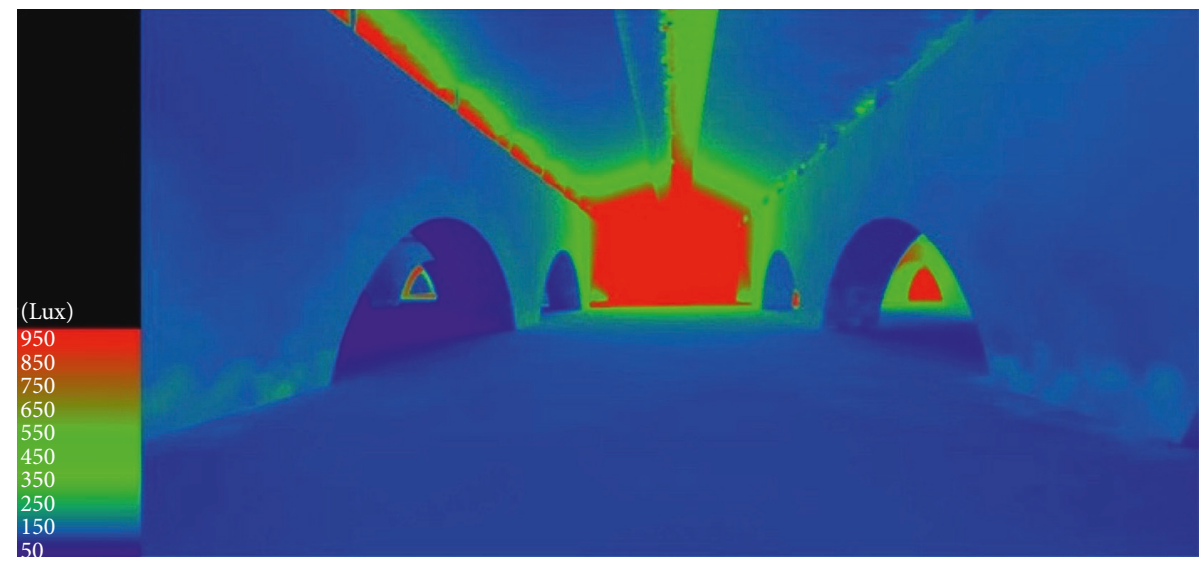

FIgURE 10: Natural daylight simulation, winter solstice. 3D illuminance representation (lx). Nave 3, Atarazanas, Seville, Spain.

\section{Conclusions}

The principle of interdisciplinary multitool cooperation is not only a complex scheme of design process, but also a key educational in the protection of industrial heritage as this case study.

There is a need for a thorough understanding of how the Sun affects climate. This is important because it has longand short-term influences and we need to know how these interact with anthropogenic effects. It is also important to understand natural factors in climate variability to give a basis upon which its future state might be predicted.

Natural lighting is an important factor to evaluate the quality of light environment and solar radiation. It not only can improve the visual comfort, but also can save energy consumption.

Using advanced modelling tools can help the design team (architects and engineers) to enhance daylighting availability and improve a new design and its distribution. This way lets us to implement new uses and restorations of the industrial heritage that are already built where we do not have the chance to start from scratch. In this way, as it has been illustrated in this case study of the Atarazanas, it provides a more comfortable environment, in addition to a reduction in energy consumption.

To conclude, it is worth noting how important the interaction of the different climatic aspects is in our industrial heritage for its better conservation and thus enable new uses in different new contexts that the future holds.

\section{Conflicts of Interest}

The author declares that there are no conflicts of interest regarding the publication of this paper.

\section{References}

[1] M. A. Rosen, "Engineering sustainability: a technical approach to sustainability," Sustainability, vol. 4, no. 9, pp. 2270-2292, 2012.

[2] S. Attia, J. I. M. Hensen, I. Beltran, and A. De Herde, "Selection criteria for building performance simulation tools. Contrasting architects' needs," Journal of Building Performance Simulation, vol. 5, no. 3, pp. 155-159, 2012.

[3] C. E. Ochoa, M. B. C. Aries, and J. I. M. Hensen, "State of the art in lighting simulation for building science: a literature 
review," Journal of Building Performance Simulation, vol. 5, no. 4, pp. 209-233, 2012.

[4] C. Peng, T. Ming, J. Cheng, Y. Wu, and Z. R. Peng, "Modeling thermal comfort and optimization local renewal strategies-a case study of Dazhimen meighborhood in Wuhan City," Sustainability, vol. 7, no. 3, pp. 3109-3128, 2015.

[5] J. B. Guinee, R. Heijungs, G. Huppes et al., "Life cycle assessment: past, present, and future," Environmental Science and Technology, vol. 45, no. 1, pp. 90-96, 2010.

[6] A. K. Mishra and M. Ramgopal, "Field studies on human thermal comfort-an overview," Building and Environment, vol. 64, pp. 94-106, 2013.

[7] D. Griego, M. Krarti, and A. Hernández-Guerrero, "Optimization of energy efficiency and thermal comfort measures for residential buildings in Salamanca, Mexico," Energy and Buildings, vol. 54, pp. 540-549, 2012.

[8] J. M. Bello and A. Martín, Las Atarazanas de Sevilla a Finales de la Edad Media, Sociedad Española de Estudios Medievales, CSIC, Madrid, Spain, 2012.

[9] L. Marcos, "Integrated performance model," International Journal of Sustainable Built Environment, vol. 2, no. 2, 2013.

[10] C. Fiocchi, S. Hoque, and M. Shahadat, "Climate responsive design and the Milam residence," Sustainability, vol. 3, no. 11, pp. 2289-2306, 2011.

[11] J. B. Andrade and L. Bragança, "Analysis of the impacts of economic and social indicators to sustainability assessment," in Proceedings of the International Conference Sustainability of Constructions-Towards a Better Built Environment, Innsbruck, Australia, 2011.

[12] J. Almorox, "Estimating global solar radiation from common meteorological data in Aranjuez, Spain," Turkish Journal of Physics, vol. 35, no. 1, pp. 53-64, 2010.

[13] J. C. Minslow, E. Raymond Hunt, and S. C. Piper, "A global applicable model of daylight solar irradiance estimated for air temperature and precipitation data," Ecological Modelling, vol. 143 , no. 3 , pp. $227-243,2001$.

[14] T. Wood, "Climate analysis using autodesk ecotect weather tool and solar tool," in Proceedings of the AIA Montana Annual Fall Conference, Montana State University, Bozeman, MT, USA, September 2010.

[15] J. L. Higón Calvet, Contribuciones al Estudio del Asoleo Geométrico. Procedimientos para el Cálculo del Factor de Obstrucción Solar. Aplicaciones, Ph.D. thesis, Universidad Politécnica de Valencia, Valencia, Spain, 2004. 


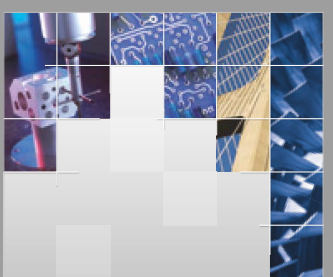

\section{Enfincering}
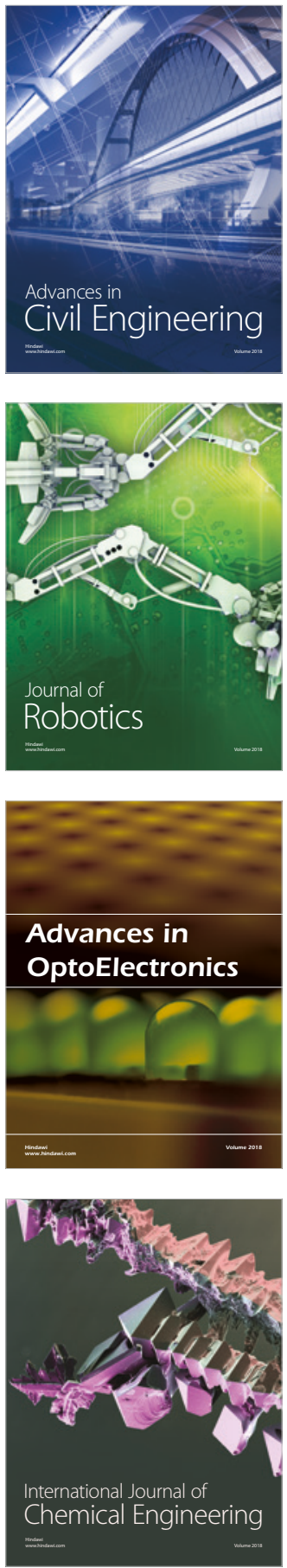

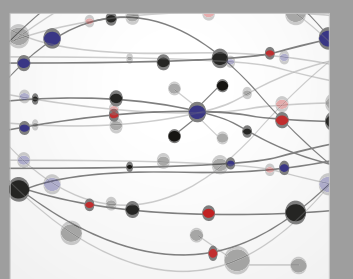

\section{Rotating \\ Machinery}

The Scientific World Journal

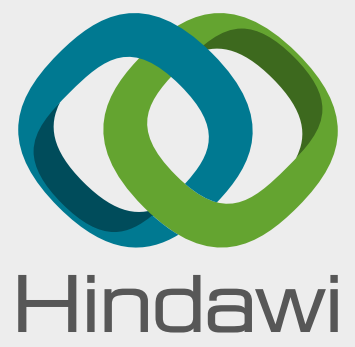

Submit your manuscripts at

www.hindawi.com
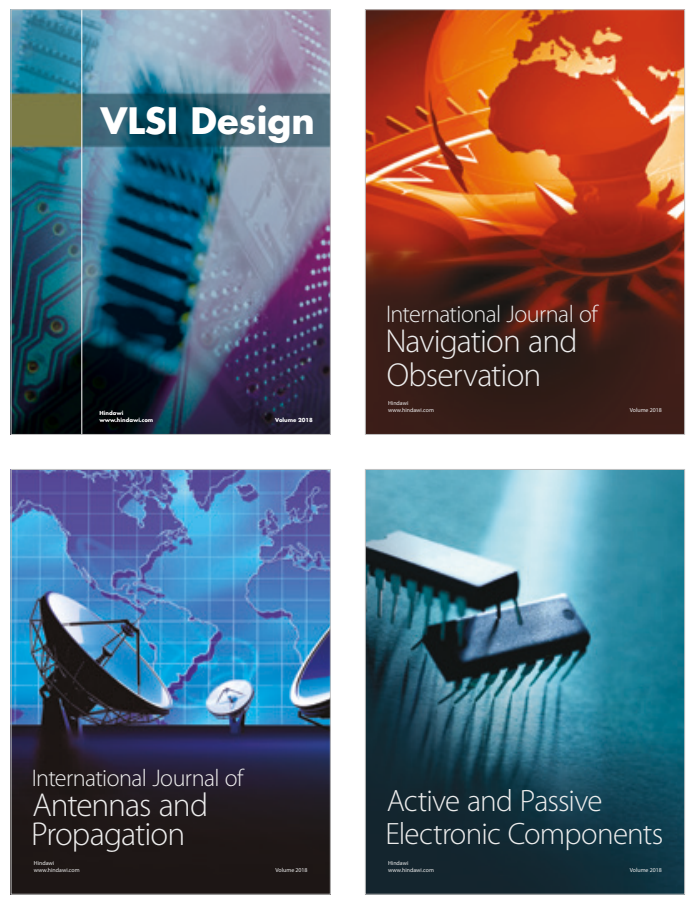
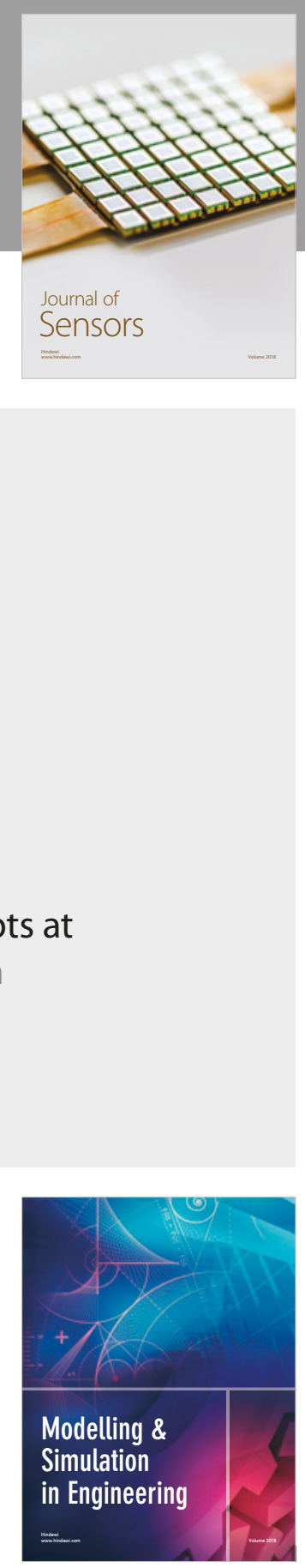

\section{Advances \\ Multimedia}
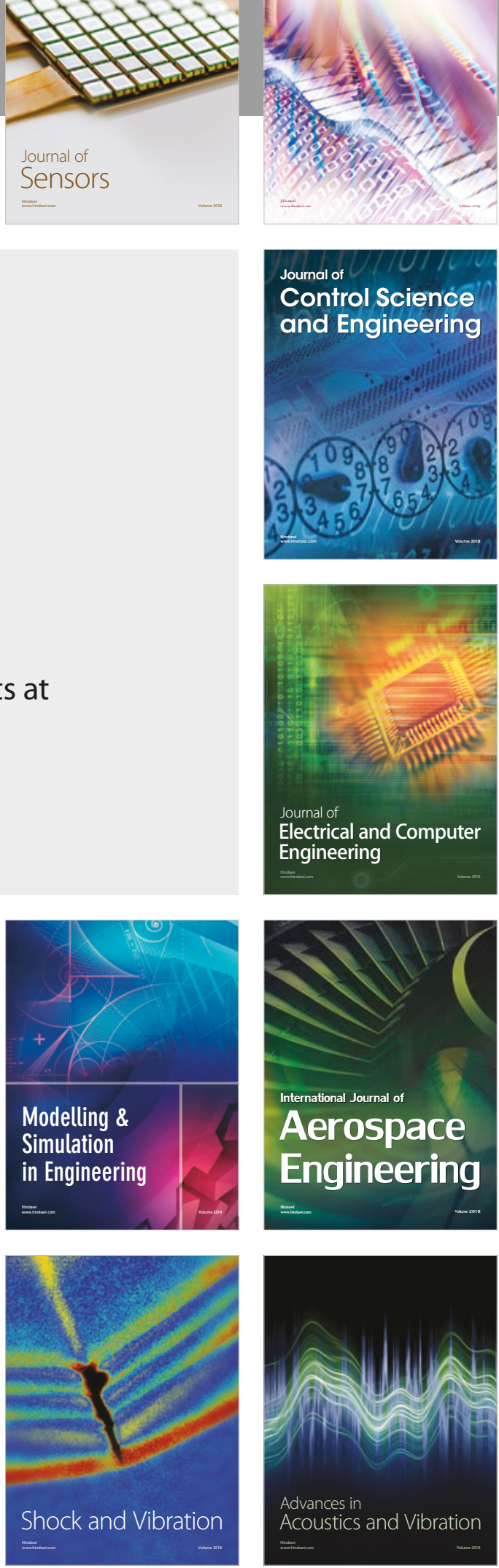